\title{
Implementation Research on Internet Plus VR in Higher Art Education Talent Cultivation*
}

\author{
Ziwei Zhou \\ Shanghai Design Institute \\ China Academy of Art \\ Shanghai, China \\ 1245790651@qq.com
}

\author{
Xueguang Zhou \\ Department of Information Security \\ Naval University of Engineering \\ Wuhan, China \\ Zxg196610@hotmail.com
}

\begin{abstract}
To explore the opportunity and challenge the internet plus VR bring with, this paper studies from 3 aspects of talent training purpose improvement, training mode reforming and training program reconstitution, and gives related analysis, suggestion and program.
\end{abstract}

Keywords - Internet plus; Virtual Reality; higher art education;training purpose; tech and art fusion

\section{INTRODUCTION}

Marked by 2015 Chinese government's Annual Work Report made by Prime Minister Li Keqiang, Internet plus has become a new hit, of which the core is the evolution and expansion of internet, reflecting the dynamic procession of internet fusing and intervening the real world with width and depth. Internet plus will evolve in 3 dimensions of space, intelligence and function [1].

VR achieves the immersion of watching, interaction of vision, hearing, touch, thinking and behavior with the VR scenes through creating digital virtual scenes [2], which has the factors of 3I: Immersion, Interaction and Imagination. The operation cost of VR technology has been decreased to a level accepted by ordinary commercial and civil enterprises, resulted in the outburst of it in 2016, which is called VR Year, many VR products have been realized and the VR industry has welcomed a promotion of tenfold increase speed [3].

Tech and art fusion is proposed by Li Zhengdao in Science and Art [4], a typical example of it in the art profession is the ad hoc profession of art and technology set up by Ministry of Education in 2012, which is subject to newest discipline fields in Degree Grants and Personnel Training Subject Catalogue published by Ministry of Education in 2011. With the coming of internet plus VR, tech and art fusion comes back to the hit again. This paper learns from the related technology and theory of internet plus VR, studies from the training purpose analysis, training mode reforming and training program construction in higher art education talent cultivation, and then gives related analysis, suggestion and program.

\section{ANALYSIS AND IMPROVEMENT OF HIGHER ART EDUCATION TALENT TRAINING PURPOSE}

The exact training purpose of Shanghai Design Institute given by the dean of China Academy of Art is that: develop humanist tradition of art academy, rely on geographical characteristics of Shanghai, integrate the advantage of international city, stress the highlights of city design, construct height of design education, cultivate talents of realistic and innovative. To accelerate the double top construction of the academy, implement three extension education reforming in major university construction project and construct height of high quality talents cultivation, the academy submit Measure of China Academy of Art Implementing Top Innovative Talents Cultivation Project in 2015 and select talents from the whole academy in all disciplines and profession. As an attempt of new graduate student select method, the project proved to work well, the selected students proved to have characteristics of open horizon, better comprehensive ability, strong subject advantage and others in common, and stored talents for building the academy to be the world class characteristic university. In addition, the academy has started to cultivate the talents according to the recruit project of academic and professional post graduate take half and half.

Nanjing Art University aims to build a domestic first-class, world famous comprehensive art university. The main task is to train advanced art talents, the main class is undergraduate and post graduate. Undergraduate education is to make students master basic theory, profession knowledge and basic skill as well as basic ability to work on the profession, while the post graduate education is to train the students with firm basic theory, deep profession knowledge and strong ability to create or research. After the introduction of General Program of Professional Degree Education Development in $27^{\text {th }}$ meeting of the Academic Degrees Committee of the State Council in January 2010, the institute actively adapted to the adjustment of graduate enrollment structure and the cultivation of academic talents and applied talents. The former mainly cultivated art theory research work of the senior specialized personnel, while the later mainly engaged in artistic creation or performance work of high-level, applied expertise [5].

This work was supported in part by the Program of Education Science Foundation of Naval University of Engineering(NUE) , under grant NUE2014110. 
The training purpose of China Communication University art design undergraduate profession is to cultivate advanced comprehensive talents engaged in both practical work of art design, film and television production, advertising planning and theory research, who owns contemporary design concept and advertising professional design knowledge and creative ability. With the mobile internet gradually embedded into people's lives, the user experience has a pivotal position in overall industry chain. The most relevant are the positions of product design, product operation and others, which are also in urgent need of position transfer of talents with relevant scientific background or some traditional art related professional personnel, the former lack relevant art knowledge and background, designing things not good looking, while the latter lack internet background and ability of product design, organization, designing things not easy to use. And good-looking and easy to use is the two indispensable important aspects of user experience. Thus, the art and technology special undergraduate profession wins the recognition of the institute. The institute cultivate student with abilities demanded by internet industry and art category [6].

Tsinghua University starts the cross discipline cultivation even earlier. The cross discipline profession cultivated by both computer department, art institute and news communication institute, Information Art \& Design profession, has started to recruit since 2009, for about 20 students each year. The project is a comprehensive platform that in tegrate art, media and technology, of which the intersection is design innovation. It lead students to conduct valid research on information art design crossing discipline through study the problem of information itself, the size of information amount, the feasibility of information visibility and other deeper ones, and achieved satisfied results. With time goes by, the second crossing discipline project of Tsinghua University, Global Innovation Exchange (GIX), has been established in 2015. The president Qiu Yong concludes the project with 3I characteristic: international, interdisciplinary, integration. The mission of GIX is to cultivate leading innovation talents with open horizon, responsibility and the ability of technology, design and operation. Tsinghua has innovated in discipline integration [7].

Through analysis above, the status quo of China higher education art talent cultivation has been introduced. The author believes that: the aim is found with our instinct, which must go through realization, adjustment and improvement. As Mark Zuckerberg put it in 2017: the goal is that we realize that we are part of something bigger than ourselves, what we need, and what we need to work harder. The goal can create real happiness. The current goal is far from the destination, there are still far ways to go.

\section{REFORMING OF HIGHER ART EDUCATION TALENT TRAINING MODE}

Talent training mode refers to the sum of the process of carrying out the talent education under the guidance of certain modern educational theories and educational thoughts, according to the specific training objectives and talent specifications, with relatively stable teaching contents and curriculum system, management system and assessment methods. The training mode of China mostly adopt the tradition of mentoring and workshop-style since ancient times, which owns its' advantages, but also has short comings like inside hatred. The student with certain hatred will be training with certain purpose, which leads to the break or disappear of the inheritance. The workshop-style is rather superior to the former one, it educate the apprenticeship through the leading of mature staff. After being familiar with the various aspects of the workshop, the apprentice can work independently and graduate.

China has a long history of higher art education, of which the most representative ones are Chinese painting and calligraphy. The Chinese painting can be divided into category of landscape, people, flowers and birds, etc. while calligraphy is divided according to font of cursive, script, regular script, etc. and style of Yan, Liu, Mao , etc.. In addition, there are also other quintessence like landscape design, yin and yang measurement and other industries. Cultivating talents above cannot be separated from the mentoring and workshop-style.

China has introduce college-style higher education training mode since 20 century, which starts to cultivate advance talents with system, plan and scale. In short, this kind of formal cultivation mode which relies on college does train a great amount of talents, which is also the mainstream talent training mode.

On the Contest of "Inquiry-based \& Small Class Teaching” of Sichuan University 2017(final) Opening Ceremony in 2017, academician Xie Heping stressed that: heuristic lectures, interactive discussion, non-standard answer test is the core of exploratory-small class teaching. To give a good lesson, the teacher must give 5 to 7 times workload of the teaching hours, similarly, the student must pour a lot of energy into preparation and after-school homework. The innovation ability will be empty talk with no effort.

Education mode will develop with the times and technology progress, China's talent training model has experienced a radio and television audio-visual education model, computer network distance education model and the current model of MOOC relying on the internet and vigorous development and of flip class education. These models are powerful complement to collegestyle talent training model. The mentoring model benefits fewer students, there may be only one beneficiary sometimes. The workshop-style can train a group of personnel with ability of assembly line of this workshop, with more tutors and apprentices. Then the college-style starts large-scale training activities and develop the education into an industry. With the progress of technology, there will be growingly advanced teaching methods, more beneficiaries, larger scale and easier sharing of education accomplishments. 
Li Yanhong, CEO of Baidu, said that: the past innovation comes from laboratory and the university, while the future innovation comes from data and scene. The innovation of higher art education mode also faces the transformation above, and the important foundation of this transformation is the rapid development of internet plus VR.

\section{TRAINING PROGRAM CONSTRUCTION IN HIGHER ART EDUCATION TALENT CULTIVATION}

It has been well known that there must be several modules of general education, profession education and comprehensive in training program of higher art education talent cultivation. The art, computer, foreign language, humanism, practical training and other contents of general education will be emphasized by every college, while the profession education and comprehensive education will be decided by the profession and employment direction demand. Take Nanjing Art Institute as an example, there are a variety of art lessons for students from every profession, department. But profession education is mainly about profession practice and lecture, group and other contents.

Tsinghua University adopt MOM mode in information art design post graduate cultivation project, which recruit students through multiple entry from liberal arts, science and engineering with methods of exemption of examinations and universal examination. And the students will be trained in one platform, which owns elective courses for arts \& design science, elective courses for journalism \& communication science and elective courses for computer science. In addition, there are advisers group with mentors, courses advisers and exit advisers for interdisciplinary subject. Multiple exit refer to the degree one obtain after graduation, which consists of journalism, artistic design and computer science. The characteristic of MOM mode is integrated design methodology, plenty of practice and program, the students gets trained with several methods.

Shanghai Design Institute, China Academy of Art performs well in the construction of personnel training program, the enterprise visual image design training program proposed by which is a good example [8]. In that program, there pay attention to cultivating students' research and analysis, research object, communication expression, team collaboration, design management and learning related laws and regulations, including advertising law, trademark law, financial system and other key elements. The basic course hour of it is 100 hours, 160 for the higher ones. The program also cooperate with China Art Design Alliance to form a healthy development of academic research.

Naval University of Engineering involves in artificial intelligence, information security, big data and other disciplines, of which the information visualization is welcomed by students. The students directed by author has designed and realized the ship dynamic distribute and monitoring system for Guangzhou port (seen in Figure 1), the author also works on VR development and realized vessel virtual display system (seen in Figure 2).

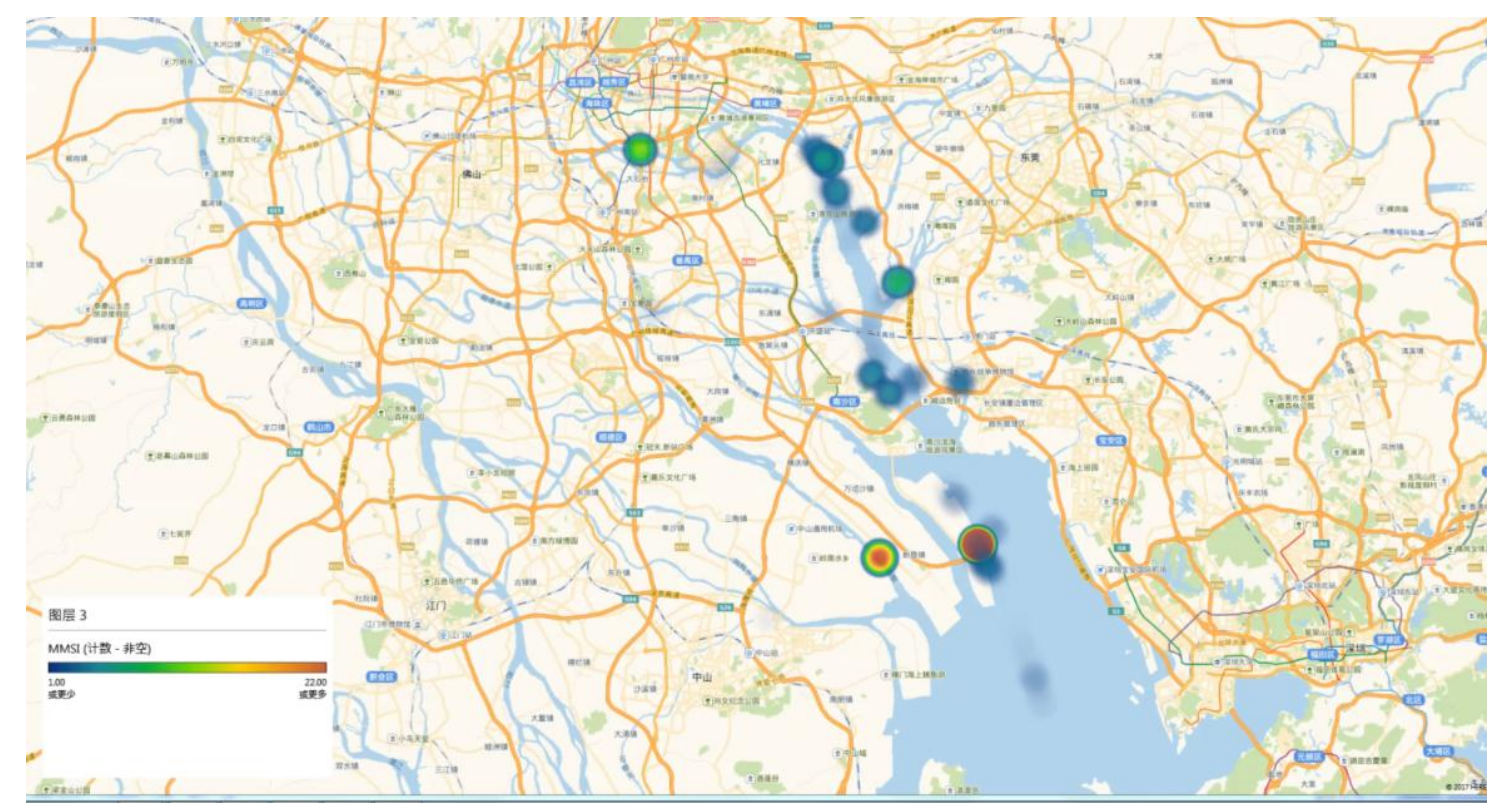

Fig. 1. Ship dynamic densit map of Guanghou port 


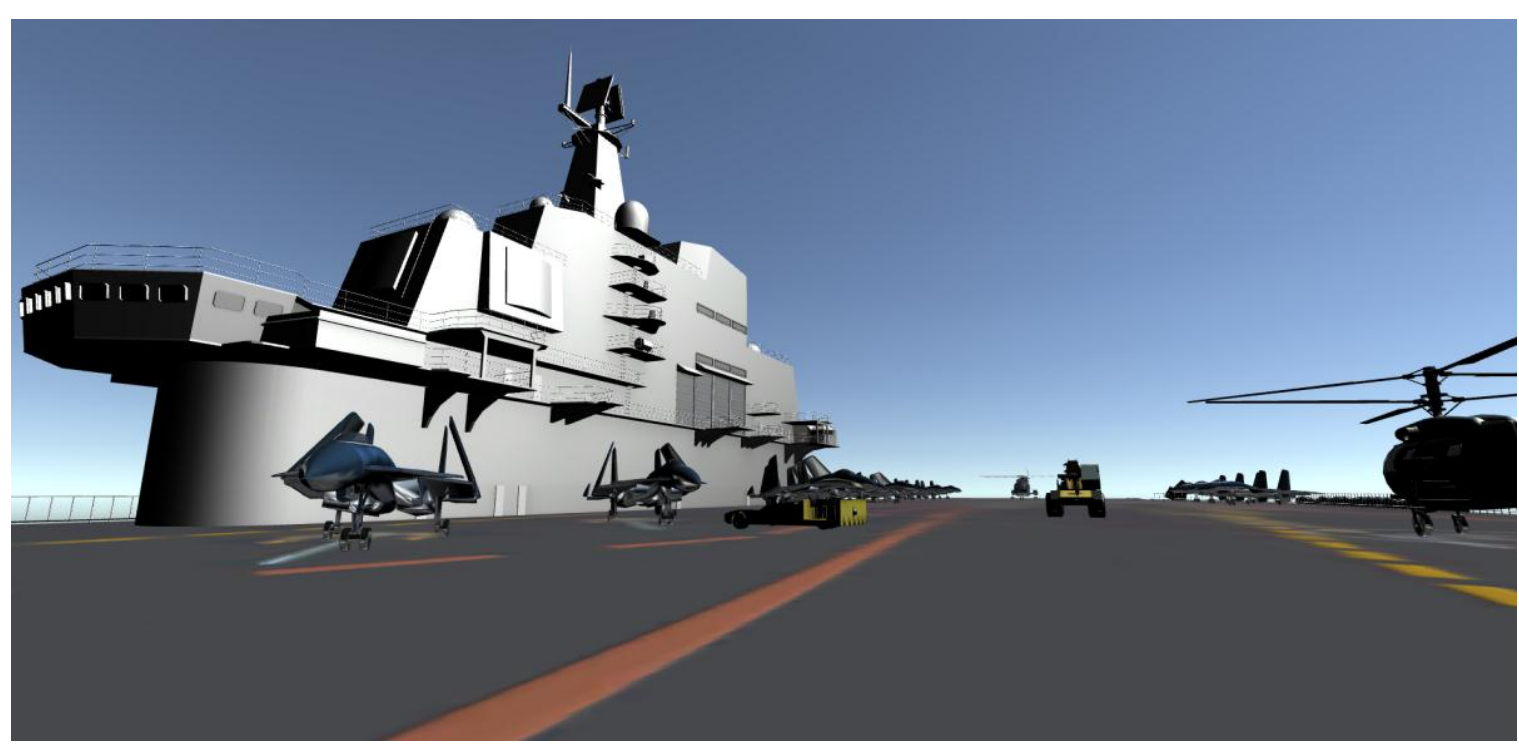

Fig. 2. Static picture of ship virtual display system

In addition, the construction of hardware is also import in training program. In art college, the establishment of VR laboratory should consider the preparations for develop ability of students, which includes preparations for hardware and software. Take VR helmet as an example, nearly $99 \%$ of the current computers cannot support graphic card for VR helmet. Thus, fundamental hardware environment demands for the support of university, otherwise the VR education is just empty talk, not talking about spreading. And the students also need to prepare for VR develop software to accept related education and research.

\section{SUMMARY}

This paper studies the training purpose, training mode and training program of higher art education. The higher art education in China has developed from academic majored to academic \& professional majored. The training mode has developed from the mentoring, workshop-style, college style to college \& internet style. Every college focus on the development of technology and the teaching methods involves broadcast, television, internet, VR etc.. The training programs are also specified, the colleges take advantage of the new technology to the education industry. Internet plus VR technology is also welcomed by the higher art education fields.

\section{ACKNOWLEDGMENT}

The authors would like to give thanks to anonymous reviewers for the comments and suggestions. We would also like to thank the University Education Science Foundation of Naval University of Engineering (NUE). This paper is part of our foundation work, the grant number is NUE2014110.

\section{REFERENCES}

[1] Liu Feng. "Future Development Trend of Internet + Education”. English Teachers. vol. 15, no.9, 2015, pp.6-8. (in Chinese).

[2] Zhao Qinping, Zhou Bin, Li Jia, Chen Xiaowu. “A Brief Survey on virtual Reality Technology”. Science \& Technology Review, vol.34, no.14, 2016, pp. 71-75(in Chinese), doi:10.3981/j.issn.1000-7857.2016.14.008.

[3] Wang Tao, Duan Youqiao. "Key Technologies and Development of VR Panoramic Video", Communications of the CCF,vol.12, no.12, 2016, pp.42-49(in Chinese).

[4] Li Zhengdao. Science and technology. Tianjin Science \& Technology.no.6, 2004, pp.38.(in Chinese).

[5] Ji Fengyun. "Exploration on Classical Training Mode Reform for Postgraduate of Arts and Design". Academic Degrees and Graduate Education.no.6, 2015, pp.17-21. (in Chinese).

[6] Chen Huan, Lu Kaifeng. "Study on Undergraduate Major Training Mode for Art and Sci-tech”. Design Teaching and Practice,no.9, 2016, pp.100-102. (in Chinese).

[7] Shi Yuanchun. "Interdisciplinary Innovation". Communications of the CCF, vol. 13, no.1, 2017, pp.55-60.(in Chinese).

[8] Kong Lily. “Training Research on Enterprise Visual Identity Design”. Shanghai Packaging. No.12, 2012, pp. 54-57. (in Chinese). 